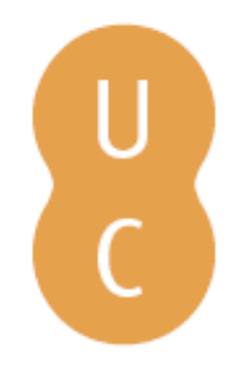

\title{
pompalina
}

\section{Fontes termo-minerais em Portugal continental e ilhas dos Açores}

Autor(es): $\quad$ Delgado, Cristina; Feio, Maria João; Gonçalves, Vítor; Raposeiro, Pedro; Almeida, Salomé F.P. de

Publicado por: Imprensa da Universidade de Coimbra

URL

persistente: URI:http://hdl.handle.net/10316.2/45894

DOI: $\quad$ DOI:https://doi.org/10.14195/978-989-26-1624-7_17

Accessed : $\quad$ 26-Apr-2023 13:30:45

A navegação consulta e descarregamento dos títulos inseridos nas Bibliotecas Digitais UC Digitalis, UC Pombalina e UC Impactum, pressupõem a aceitação plena e sem reservas dos Termos e Condições de Uso destas Bibliotecas Digitais, disponíveis em https://digitalis.uc.pt/pt-pt/termos.

Conforme exposto nos referidos Termos e Condições de Uso, o descarregamento de títulos de acesso restrito requer uma licença válida de autorização devendo o utilizador aceder ao(s) documento(s) a partir de um endereço de IP da instituição detentora da supramencionada licença.

Ao utilizador é apenas permitido o descarregamento para uso pessoal, pelo que o emprego do(s) título(s) descarregado(s) para outro fim, designadamente comercial, carece de autorização do respetivo autor ou editor da obra.

Na medida em que todas as obras da UC Digitalis se encontram protegidas pelo Código do Direito de Autor e Direitos Conexos e demais legislação aplicável, toda a cópia, parcial ou total, deste documento, nos casos em que é legalmente admitida, deverá conter ou fazer-se acompanhar por este aviso.

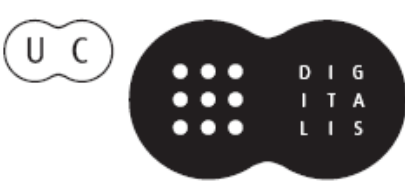


MARIA JOÃO FEIO

VERÓNICA FERREIRA

(EDS.)

\section{IMPRENSA DA \\ UNIVERSIDADE \\ DE COIMBRA \\ COIMBRA \\ UNIVERSITY \\ PRESS}

\section{RIOS DE PORTUGAL COMUNIDADES, PROCESSOS E ALTERAÇÕES}




\title{
CAPÍTULO 17
}

\section{FONTESTERMO-MINERAIS EM PORTUGAL CONTINENTAL E ILHAS DOS AÇORES}

\section{Cristina Delgado ${ }^{1}$, Maria João Feio ${ }^{2}$, Vítor Gonçalves ${ }^{3}$, Pedro Raposeiro ${ }^{4}$ \&} Salomé F.P. de Almeida ${ }^{5}$

\begin{abstract}
${ }^{1}$ GeoBioTec - Unidade de Investigação Geobiociências, Geotecnologias e Geoengenharias e Departamento de Biologia, Universidade de Aveiro, Portugal e Departamento de Ecologia e Biologia Animal, Universidade de Vigo, Espanha e MARE - Centro de Ciências do Mar e do Ambiente, Departamento de Ciências da Vida, Faculdade de Ciências e Tecnologia, Universidade de Coimbra, Portugal cdelgado.cristina@gmail.com ${ }^{2}$ MARE - Centro de Ciências do Mar e do Ambiente, Departamento de Ciências da Vida, Faculdade de Ciências e Tecnologia, Universidade de Coimbra, Portugal, mjf@ci.uc.pt ${ }^{3} \mathrm{CIBIO}$ - Centro de Investigação em Biodiversidade e Recursos Genéticos, InBIO Laboratório Associado, Pólo dos Açores, Departamento de Biologia da Universidade dos Açores, Portugal, vitor.mc.goncalves@uac.pt ${ }^{4}$ CIBIO - Centro de Investigação em Biodiversidade e Recursos Genéticos, InBIO Laboratório Associado, Pólo dos Açores, Departamento de Biologia da Universidade dos Açores, Portugal, pedro.mv.raposeiro@uac.pt

${ }^{5}$ GeoBioTec - Unidade de Investigação Geobiociências, Geotecnologias e Geoengenharias e Departamento de Biologia, Universidade de Aveiro, Portugal, salmeida@ua.pt
\end{abstract}

Resumo: As águas termo-minerais apresentam diferentes quantidades de sais minerais que dependem do tempo e da natureza das rochas com as quais a água esteve em contacto. Dentro destas, as águas termais são aquelas cuja temperatura é mais elevada que a temperatura ambiente, em pelo menos $5^{\circ} \mathrm{C}$. Portugal é um dos países da Europa mais rico neste tipo de ocorrências termo-minerais, sendo a maioria das fontes 
termais sulfúreas devido ao seu conteúdo em formas reduzidas de enxofre. Cinco das nove ilhas dos Açores possuem também águas termais de origem vulcânica. Os organismos que habitam estas fontes (a maioria são procariotas) são considerados termófilos por se conseguirem reproduzir em altas temperaturas. A flora associada a estes sistemas termo-minerais é formada por espécies macro e microscópicas em associação complexa e estreitamente relacionadas com a mineralização, temperatura e acidez. Os organismos melhor estudados em fontes termais são algas azuis ou cianobactérias, diatomáceas e sulfobactérias. Neste capítulo descrevem-se os tipos de águas termo-minerais, a sua distribuição no Mundo e em Portugal e os organismos que nelas se encontram.

Palavras-chave: águas minerais, áreas vulcânicas, diatomáceas, organismos termófilos, temperatura

\section{1. Águas termo-minerais}

As águas termo-minerais são consideradas importantes recursos naturais, sobretudo devido à sua utilização em terapia médica, turismo, recreação, reabilitação e consumo ${ }^{1}$. Depois da Segunda Guerra Mundial, a investigação das águas minerais teve um grande incremento como resultado do crescente interesse dos consumidores e dos seus potenciais usos múltiplos ${ }^{2}$.

As águas termo-minerais apresentam diferentes quantidades de sais minerais e oligoelementos (elementos químicos inorgânicos necessários aos seres vivos em pequenas quantidades, que desempenham diversas funções metabólicas nos organismos, principalmente na formação de enzimas vitais aos diversos processos bioquímicos realizados pelas células). A quantidade de iões, presentes na água, 
depende do tempo e da natureza das rochas com as quais a água esteve em contacto ${ }^{3}$. De acordo com as características das águas subterrâneas, estas podem classificar-se como: (i) águas minerais naturais, (ii) águas de nascente ou (iii) águas termais. As duas primeiras podem ser consumidas pelo homem e comercializadas sem adição de substâncias químicas ou outros aditivos. A composição química das águas minerais naturais é estável ao longo do tempo, ao contrário das de nascente, o que requer que esta seja engarrafada no local onde nasce (p. ex., Pedras Salgadas).

As águas termais distinguem-se pela sua temperatura mais elevada que a temperatura ambiente (em pelo menos $5^{\circ} \mathrm{C}$ ) e, como tal, possuem várias aplicações nomeadamente em balneologia, aquecimento de instalações e produção de energia elétrica ${ }^{4}$. Devido à sua temperatura elevada, estas águas podem dissolver mais rapidamente as rochas. Entre as fontes termais, aquelas que se denominam thermal springs têm temperaturas da água claramente mais altas do que a temperatura média anual do ar, enquanto as hot springs têm temperaturas que excedem a temperatura do corpo humano ${ }^{3}$. Estas águas termais podem ter origens diferentes: circularem próximo de uma fonte de calor no interior da Terra (como em regiões vulcânicas como os Açores) ou serem águas de origem muito profunda que sobem à superfície deslocando-se através de falhas (tal como acontece ao longo da falha de Régua-Verin onde se situam algumas das águas termais mais importantes de Portugal como, por exemplo, as termas de Chaves).

\section{Tipos de águas termo-minerais}

De acordo com a legislação europeia $(2009 / 54 / C E)^{5}$, as águas minerais classificam-se de acordo com a sua composição química. Tendo em conta a concentração total de sais minerais dissolvidos $(\mathrm{mg} / \mathrm{L})$, calculada como resíduo fixo, na água podemos encontrar: (i) água 
muito pouco mineralizada, cujo teor em sais minerais não é superior a $50 \mathrm{mg} / \mathrm{L}$; (ii) água oligomineral ou pouco mineralizada, cujo teor em sais minerais não é superior a $500 \mathrm{mg} / \mathrm{L}$; (iii) água mineralizada, cujo teor em sais minerais é entre 500 e 1500 mg/L; e (iv) água rica em sais minerais, cujo teor em sais minerais é superior a $1500 \mathrm{mg} / \mathrm{L}$.

Se tivermos em conta a quantidade do ião dominante podemos classificar a água nos seguintes tipos:

(i) bicarbonatada, com elevada concentração de bicarbonato (o teor em bicarbonato é superior a $600 \mathrm{mg} / \mathrm{L}$ ), são águas geralmente frias e alcalinas e utilizam-se para aliviar os sintomas de doenças gastrointestinais;

(ii) sulfatada, o teor em sulfatos é superior a $200 \mathrm{mg} / \mathrm{L}$ mas se o enxofre dissolvido na água é reduzido a sulfureto de hidrogénio, origina águas sulfúreas;

(iii) cloretada, o teor em cloro é superior a $200 \mathrm{mg} / \mathrm{L}$;

(iv) fluoretada, o teor em flúor é superior a $1 \mathrm{mg} / \mathrm{L}$;

(v) sódica, o teor em sódio é superior a $200 \mathrm{mg} / \mathrm{L}$;

(vi) cálcica, o teor em cálcio é superior a $150 \mathrm{mg} / \mathrm{L}$;

(vii) magnesiana, o teor em magnésio é superior a $50 \mathrm{mg} / \mathrm{L}$;

(viii) acidulada, o teor em gás carbónico livre é superior a $250 \mathrm{mg} / \mathrm{L}$;

(xix) ferruginosa, o teor em ferro bivalente é superior a $1 \mathrm{mg} / \mathrm{L}$, e são águas utilizadas para tratamento de doenças hepáticas;

(x) água pobre em sódio, o teor em minerais é baixo $\left(\mathrm{Na}^{+}<\right.$ $20 \mathrm{mg} / \mathrm{L}$ ), sendo adequada para todas as pessoas, inclusive bebés e gestantes, e é indicado para o consumo diário com fins diuréticos.

As águas minerais naturais provêm de fontes naturais ou perfurações de águas subterrâneas, procedentes de aquíferos, e podem ser efervescentes quando libertam espontaneamente, na origem ou após engarrafamento, gás carbónico nas condições normais de tempera- 
tura e pressão. Repartem-se em três categorias às quais se aplicam, respetivamente, as seguintes denominações da Diretiva Europeia 5 :

(i) água mineral natural gasosa, o teor em gás carbónico proveniente da nascente é o mesmo que à saída da nascente;

(ii) água mineral natural reforçada com gás carbónico natural, o teor em gás carbónico proveniente do lençol ou mesmo do jazigo é superior ao verificado à saída da nascente;

(ii) água mineral natural gaseificada, água à qual foi adicionado gás carbónico de outra origem que não seja o lençol ou o jazigo de onde esta água provém.

\section{Distribuição das águas termais}

\subsection{No Mundo}

As águas termais, geralmente, aparecem em áreas com alta atividade geotérmica (produzida a partir do calor proveniente do interior do planeta Terra), onde ocorrem grandes acumulações de água quente entre rochas impermeáveis (aquelas que impedem a migração dos fluidos, sejam água, petróleo ou gás, até à superfície) ${ }^{6}$. Estas áreas com atividade geotérmica são muito comuns em torno dos limites das placas tectónicas (fragmentos da crosta terrestre). Atualmente, a Terra possui 12 placas tectónicas principais e dezenas de subplacas menores (seus movimentos são responsáveis pelos terremotos, maremotos e erupções vulcânicas) ou áreas vulcânicas, mas a literatura referente às fontes termais é escassa. Temperaturas inferiores a $50^{\circ} \mathrm{C}$ são comuns na Terra, enquanto temperaturas superiores a $55-60^{\circ} \mathrm{C}$ são muito mais raras na natureza e estão associadas quase exclusivamente a ambientes geotérmicos (Figura 17.1). 


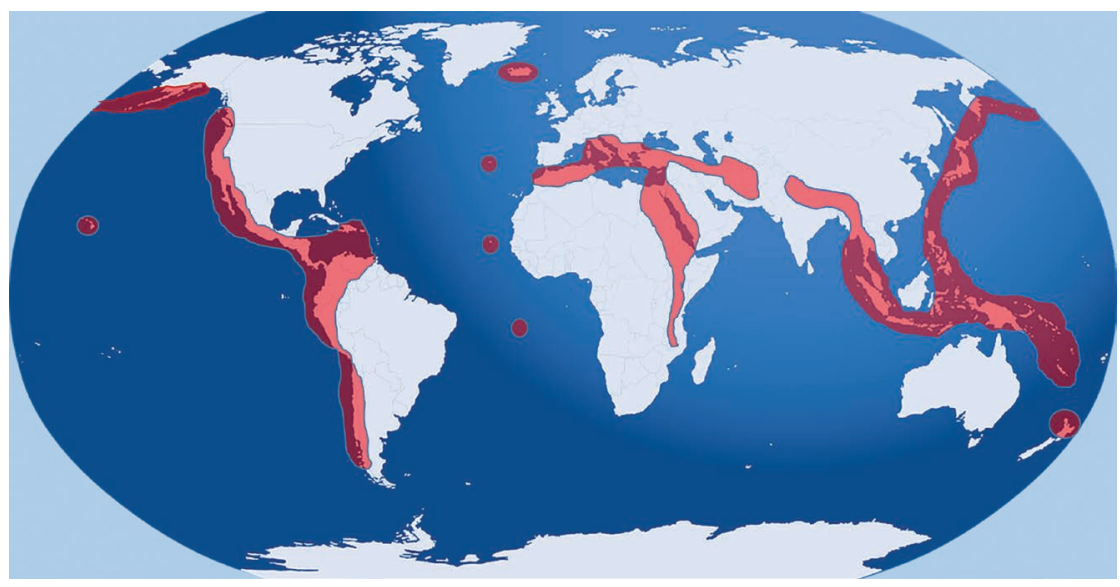

Figura 17.1. Localização das áreas geotérmicas mais quentes do mundo (a vermelho; dados obtidos da US Geological Survey, www.usgs.gov).

A atividade térmica está concentrada em áreas muito diversas como, por exemplo a costa ocidental dos Estados Unidos (parque de Yellowstone), Islândia, Nova Zelândia (Rotorua) e Japão ${ }^{7}$. Há ainda fontes termais em pequenas áreas disseminadas pela Europa central e meridional, Ásia, Índias Orientais, Melanésia, África e América do $\mathrm{Sul}^{8}$.

\subsection{Em Portugal continental}

A região noroeste da Península Ibérica é particularmente rica em ocorrências hidrominerais sulfatadas alcalinas? 9 . As nascentes termais localizam-se principalmente na zona norte e centro do Maciço Hespérico, designadamente na Zona Centro-Ibérica, estando a sua distribuição intimamente relacionada com grandes acidentes tectónicos, como é o caso do acidente Penacova-Régua-Verin ${ }^{10}$. Portugal é um dos países da Europa mais rico neste tipo de ocorrências termo-minerais ${ }^{11}$, com nascentes termais situadas em faixas 
tectonizadas do Maciço antigo e faixas sedimentares ocidentais ${ }^{12}$. Em todo o território continental ${ }^{10}$, estão identificadas 52 insurgências com temperaturas superiores a $20^{\circ} \mathrm{C}$, encontrando-se a maioria no norte e no centro de Portugal ${ }^{13}$, devido às características geológicas e estruturais destas zonas.

Portugal contempla nove tipos hidrogeoquímicos bem definidos de águas minerais ${ }^{14}$ : sulfatada sódica, gasocarbónica, bicarbonatada sódica, bicarbonatada cálcica e/ou magnesiana, cloretada sódica, cloretada sódica em ambiente metalífero, sulfatada cálcica em ambiente evaporítico, sulfatada cálcica em ambiente metalífero e oxidrilada. A maioria das fontes termais de Portugal (Tabela 17.1) são sulfúreas caracterizando-se pelo cheiro a "ovos podres" devido ao seu conteúdo em formas reduzidas de enxofre? .

As fontes termais mais quentes do continente português estão localizadas no norte do país, ao longo de uma grande falha com cerca de $200 \mathrm{~km}$ de comprimento e orientação NE-SW, que se estende em território nacional desde a fronteira a norte de Chaves até uma área a sul de Penacova, e que atinge uma profundidade de $30 \mathrm{~km}^{15}$.

É ao longo dessa linha que surgem as águas quentes de Chaves (Figura 17.2), mas também numerosas emanações de águas mais frias e salinas, ricas em $\mathrm{CO}_{2}$ : Vilarelho de Raia, Campilho, Vidago, Sabroso e Pedras Salgadas (Figura 17.2). 

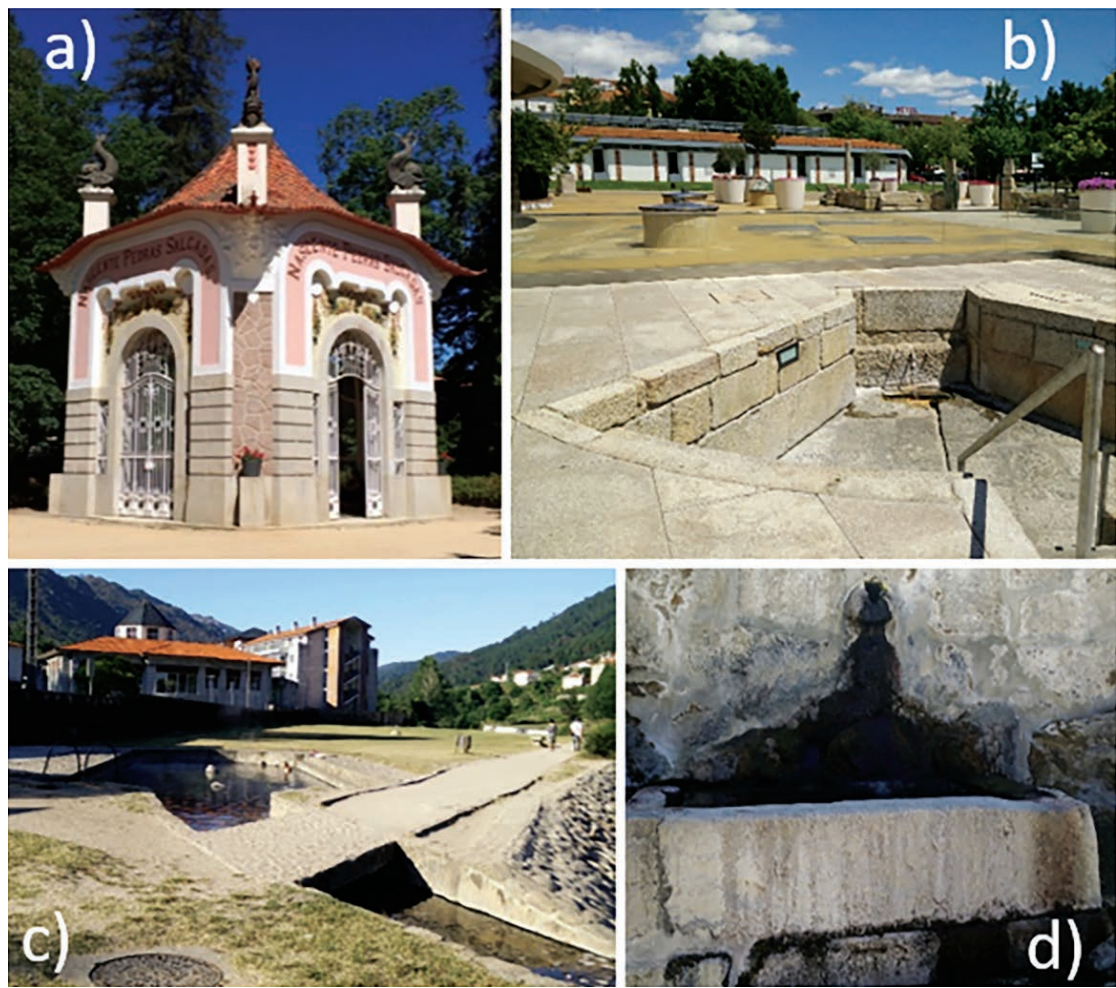

Figura 17.2. Fontes termais de Portugal: a) nascente de Pedras Salgadas; b) termas de Chaves; c) termas de Torneiros (Parque Natural do Gêres-Xures); e d) termas de São Lourenço. Fotografias: Cristina Delgado. 


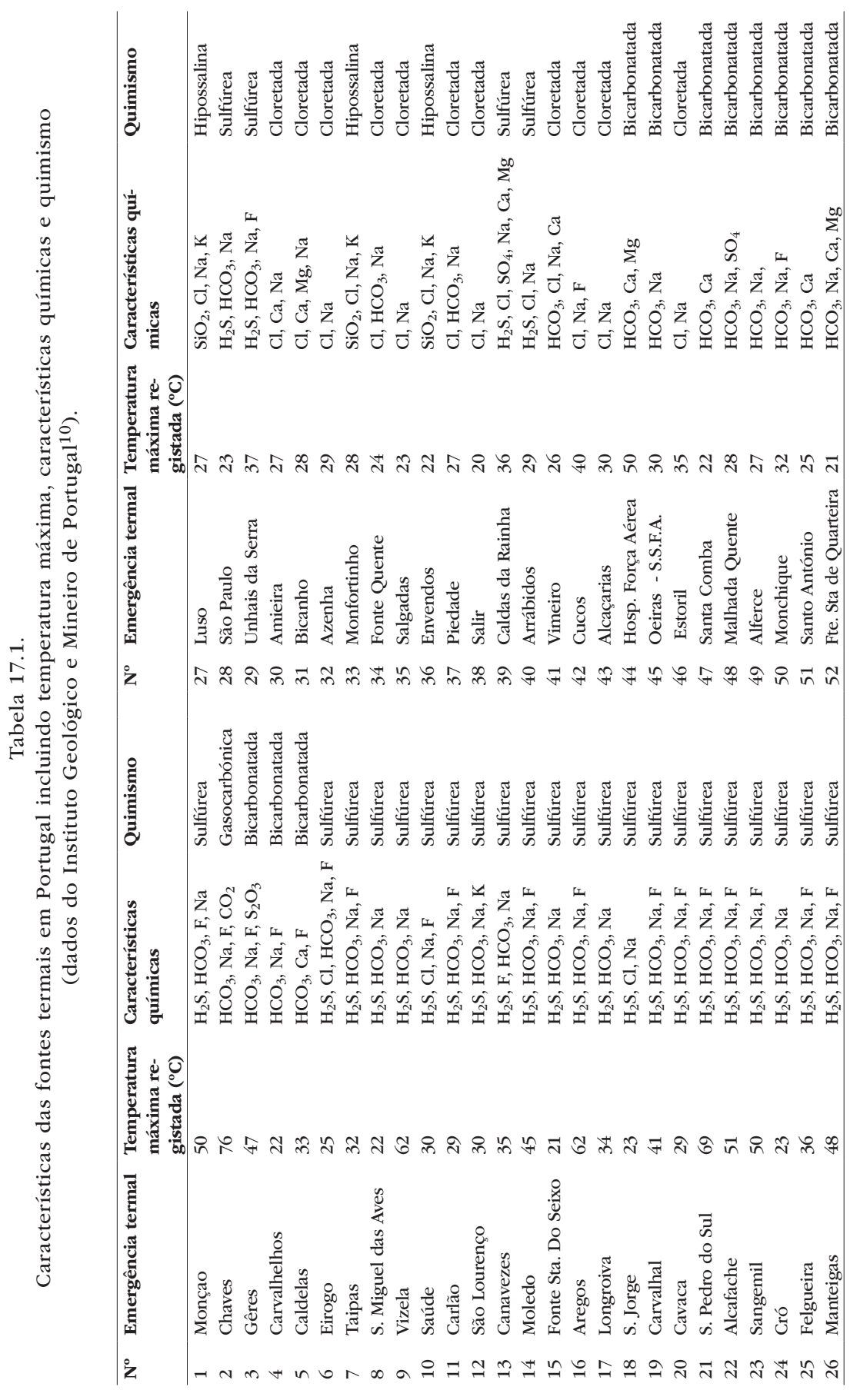




\subsection{Nas ilhas dos Açores}

As ilhas dos Açores possuem uma grande quantidade de águas termais que, no entanto, têm uma origem diferente das águas termo-minerais de Portugal continental. Devido à sua localização na junção de três placas tectónicas (Euroasiática, Africana e Americana), o arquipélago apresenta uma intensa atividade vulcânica que origina a circulação das águas subterrâneas perto de fontes de calor no interior da Terra. Esta interação entre aquíferos e fontes de calor subjacentes leva à emergência de numerosas nascentes termais e fumarolas (conhecidas nos Açores por caldeiras), normalmente associadas a vulcões centrais do Quaternário, como nas ilhas São Miguel, Terceira, Faial e Graciosa, ou anteriores ao Quaternário como na ilha das Flores ${ }^{16}$. São conhecidas fontes termais em 5 das 9 ilhas que compõem o arquipélago dos Açores: São Miguel, Terceira, Graciosa, Faial e Flores. Um estudo recente sobre as características das águas minerais dos Açores revela a existência de 79 fontes termais no arquipélago $^{17}$. A ilha com maior número de fontes termais é São Miguel $^{17}$ com fontes maioritariamente associadas aos vulcões do Fogo (p.ex., Ladeira da Velha, Caldeiras da Ribeira Grande, Caldeira Velha, Lombadas) e das Furnas (p.ex., Caldeiras da Lagoa das Furnas, Caldeiras das Furnas, Poça da Tia Silvina, Poça da Dona Beija) mas também nos Mosteiros e na Ferraria (Figura 17.3). 

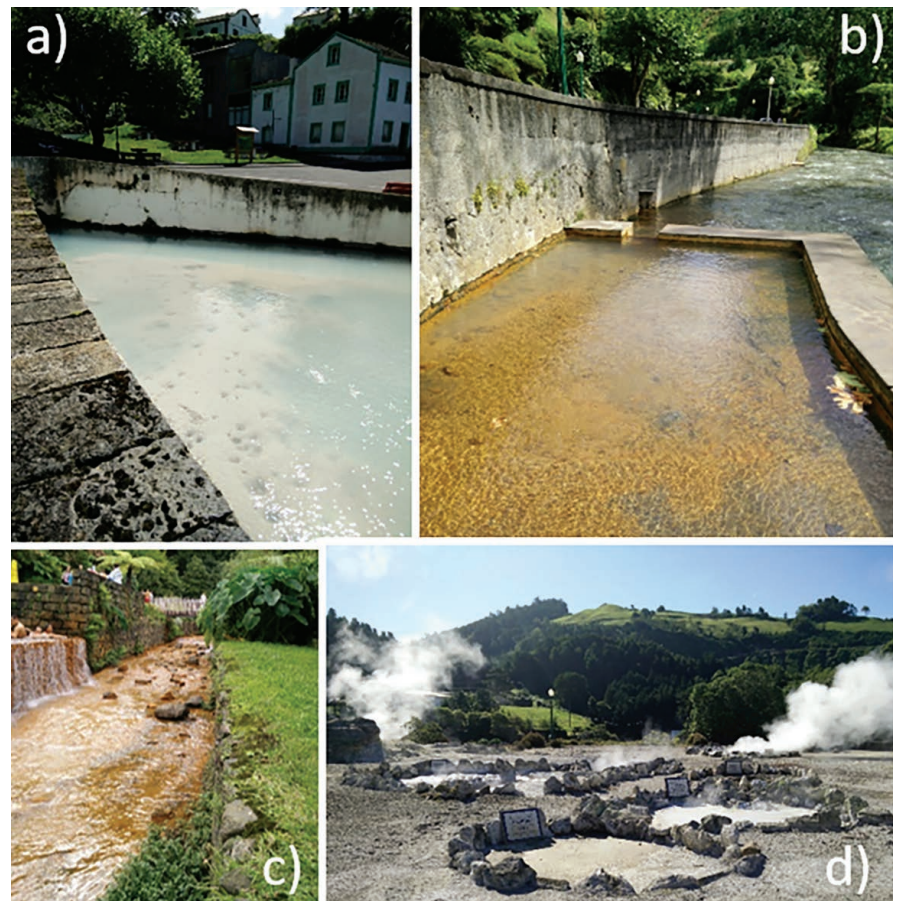

Figura 17.3. Nascentes da ilha de São Miguel (Açores): a) caldeiras da Ribeira Grande; b) Poça da Tia Silvina; c) Poça da Dona Beija; e d) caldeiras das Furnas. Fotografias: Cristina Delgado.

$\mathrm{Na}$ Graciosa e Faial encontram-se fontes termais na costa sudeste de ambas as ilhas (Termas do Carapacho e Termas do Varadouro, respetivamente), nas Flores na costa sul da ilha (Lagedo) e na Terceira na caldeira de Santa Bárbara.

Nos Açores podemos encontrar três tipos de águas termais: (i) nascentes termais e caldeiras de águas sulfatadas provenientes de aquíferos superficiais aquecidos por vapor de um sistema hidrotermal localizado em profundidade ${ }^{16}$; (ii) caldeiras com emanações de águas bicarbonatadas sódicas que provêm de aquíferos situados a baixa profundidade aquecidos a temperaturas de $150-160^{\circ} \mathrm{C}$ por lava remanescente do vulcanismo mais recente ${ }^{16}$; e (iii) nascentes termais de águas cloretadas sódicas provenientes do aquífero basal em que a 
água do aquífero se mistura com água do mar e é aquecida pelo magma subjacente ${ }^{16}$. Contrariamente aos dois primeiros, este último tipo de nascentes termais emerge a baixa altitude junto à linha de costa.

\section{Organismos que habitam as fontes termais}

Principalmente a partir de meados do século XIX começaram a ser feitas observações de organismos que vivem em águas termais ${ }^{18}$. Os organismos destas fontes são considerados termófilos por se conseguirem reproduzir a altas temperaturas. No entanto, o limite superior de tolerância das espécies varia com o grupo de organismos, sendo menor para os organismos multicelulares e maior para os organismos unicelulares ${ }^{19}$. A temperatura que os organismos conseguem tolerar depende do grupo a que pertencem: $110-115^{\circ} \mathrm{C}$ para os archaea, $70-90^{\circ} \mathrm{C}$ para os microrganismos procarióticos, $55-62^{\circ} \mathrm{C}$ para microrganismos eucarióticos, $45-50^{\circ} \mathrm{C}$ para plantas e $38-50^{\circ} \mathrm{C}$ para animais ${ }^{19}$. A incapacidade dos eucariotas crescerem a temperaturas tão elevadas como os procariotas pode estar relacionada com a complexidade da membrana celular que é maior nos eucariotas. De forma similar, os procariotas fotossintéticos não crescem a temperaturas tão elevadas como os não fotossintéticos devido à maior complexidade do sistema de membrana fotossintética ${ }^{18}$.

A temperatura não é, no entanto, o único grande desafio dos organismos das fontes termais uma vez que estas águas quentes têm elevadas concentrações de iões inorgânicos $\left(\mathrm{Ca}^{2+}, \mathrm{Mg}^{2+}, \mathrm{Na}^{+}, \mathrm{HCO}_{3}^{-}\right.$, $\mathrm{SO}_{4}^{2-}, \mathrm{Cl}^{-}, \mathrm{Si}$ e $\mathrm{H}_{2} \mathrm{~S}$ ) e um $\mathrm{pH}$ bastante ácido ou básico ${ }^{20}$. A este tipo de condições só conseguem sobreviver organismos altamente adaptados como os químio-autotróficos e as bactérias heterotróficas.

A dinâmica da rede alimentar das fontes termais não é bem compreendida. Em sistemas muito quentes $\left(>70^{\circ} \mathrm{C}\right)$, os bacteriófagos podem ser o único predador de bactérias e cianobactérias ${ }^{21}$. Outros 
consumidores ocorrem em condições menos extremas, mas poucos seres multicelulares toleram temperaturas superiores a cerca de $50^{\circ} \mathrm{C}$. Perto deste limite encontram-se invertebrados ostrácodes, ácaros aquáticos e rotíferos, mas pouco se sabe sobre a sua dinâmica ou redes alimentares. As moscas de salmoura (Paracoenia, Ephydra) colocam ovos em tapetes microbianos no Yellowstone Park dentro da faixa dos $30-40^{\circ} \mathrm{C}$ e ambos estádios, adulto e larva, consomem algas e bactérias ${ }^{18}$.

A flora associada a estes sistemas termo-minerais é formada por espécies macro e microscópicas em associação complexa e estreitamente relacionadas com a mineralização, temperatura, $\mathrm{pH}$, entre outras. Os organismos melhor estudados em fontes termais são algas azuis ou cianobactérias, diatomáceas e sulfobactérias diretamente relacionadas com a mineralização e oxidação do ácido sulfídrico a sulfuretos até liberar enxofre. Em Portugal, esse estudo é ainda muito reduzido $22-26$ desconhecendo-se a maioria dos organismos que habitam as suas águas termais.

\subsection{Cianobactérias}

As cianobactérias são os organismos fotossintéticos mais comuns em águas termais, com um limite de tolerância superior a $74^{\circ} \mathrm{C}^{27}$. As cianobactérias das águas termais incluem espécies de géneros unicelulares e coloniais como Aphanocapsa, Chroococcus, Cyanothece e Synechococcus, e filamentosos como Mastidocladus laminosus, Geitlerinema e Leptolyngbya 27,28 . As cianobactérias dominam as comunidades das fontes termais mais quentes enquanto a temperaturas mais moderadas as comunidades são mais diversificadas. É o caso do género Oscillatoria, que domina as comunidades de uma fonte termal a $62^{\circ} \mathrm{C}$ na Costa Rica, enquanto as comunidades de fontes próximas a $35-36^{\circ} \mathrm{C}$ incluem também géneros de cianobactérias como Phormidium e Lyngbya e diatomáceas como Pinnularia. Em fontes 
termais mais frias proliferam outras diatomáceas (Achnanthidium, Pinnularia) e também algas verdes (Spirogyra, Mougeotia) ${ }^{29}$.

Os estudos recentes sobre as cianobactérias que integram os biofilmes, presentes nas fontes termais dos Açores, revelam a existência de uma elevada diversidade destes organismos ${ }^{24,26}$, alguns dos quais com aplicações biotecnológicas ${ }^{26}$. O Banco de Microalgas e Cianobactérias dos Açores integra atualmente 12 isolados de cianobactérias termais pertencentes a 6 géneros diferentes (Chlorogloeopsis, Coleospermum, Leptolyngbya, Mastigocladus, Microchaete e Phormidium ${ }^{26}$. Entre as espécies mais frequentes destacam-se Leptolyngbya gelatinosa, Microchaete bulbosa, Chlorogloeopsis fritschii e Mastigocladus laminosus (Figura 17.4).

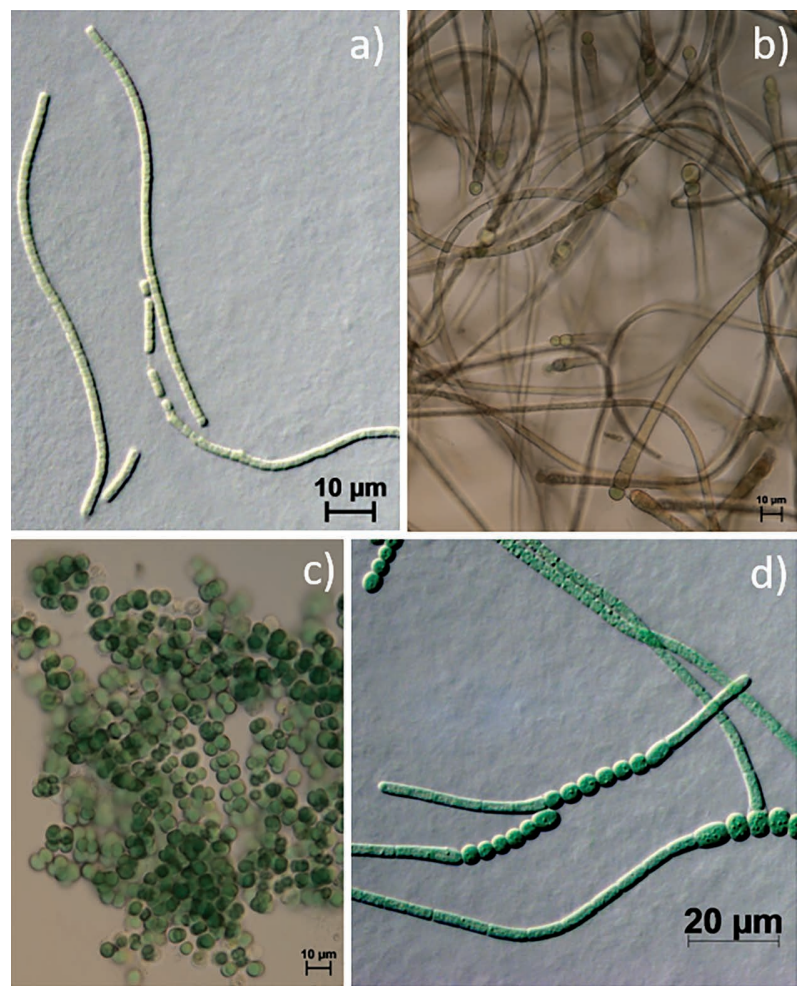

Figura 17.4. Espécies de cianobactérias características de águas termais dos Açores: a) Leptolyngbya gelatinosa; b) Microchaete bulbosa; c) Chlorogloeopsis fritschii; e d) Mastigocladus laminosus. 


\subsection{Algas eucariotas}

Existem poucas algas eucariotas termofílicas e estas estão restringidas a máximos de aproximadamente $55^{\circ} \mathrm{C}^{30}$. O limite superior para as algas eucariotas fotossintéticas é de cerca de $57^{\circ} \mathrm{C}$. A alga vermelha Cyanidium caldarium que se encontra nas fontes termais tem um ótimo de temperatura de $45^{\circ} \mathrm{C}^{20}$. Nas fontes termais é comum observarem-se diferentes zonas de cores correspondente ao gradiente de tolerância das espécies.

As diatomáceas são um grupo complexo de algas eucariotas fotossintéticas unicelulares pigmentadas (Capítulo 4) e encontram-se entre os grupos de algas eucarióticas com maior número de espécies termófilas. A diversidade deste grupo baseia-se na morfologia das suas frústulas com formas com simetria radiada ou bilateral ${ }^{20}$. O seu ciclo de vida curto permite observar uma resposta rápida das comunidades a fatores ambientais em mudança e, por isso, são recomendados como bioindicadores na avaliação da qualidade das águas doces (Diretiva Quadro da Água - DQA ${ }^{31}$ ) (Capítulos 4 e 14). As diatomáceas não são consideradas um grupo termófilo, mas a distribuição ubíqua de diatomáceas neste tipo de águas foi documentada em estudos taxonómicos e ecológicos ${ }^{32}$. Foram registadas diatomáceas em fontes termais de vários pontos do mundo, tais como em África ${ }^{33}$, nos Açores ${ }^{25}$, na Macedónia ${ }^{4}$, na Islândia e na Nova Zelândia ${ }^{31}$. No noroeste da Península Ibérica existem apenas alguns registos de diatomáceas dispersos na Galiza 34,35 mas nenhum deles inclui dados de Portugal.

Nesta área do noroeste da Península Ibérica iniciou-se, há cerca de dois anos, o estudo das diatomáceas de águas termais. Foram identificados um total de 124 taxa de diatomáceas em águas com temperaturas entre 20,9 e $42,4^{\circ} \mathrm{C}$. As diferenças nas comunidades dessas algas é explicada pelas diferenças na temperatura da água (comunidades diferentes abaixo dos $25^{\circ} \mathrm{C}$ e acima dos $35^{\circ} \mathrm{C}$ ) e nas concentrações de $\mathrm{SiO}_{2}, \mathrm{Na}^{+}, \mathrm{Mg}^{2+}, \mathrm{O}_{2}, \mathrm{NO}_{3}{ }^{-}, \mathrm{SO}_{4}{ }^{2-}, \mathrm{K}^{+}, \mathrm{Ca}^{2+}$ e $\mathrm{pH}^{36}$. 
A análise das comunidades indica que Achnanthidium minutissimum e Eolimna minima são comuns em todas as fontes termais enquanto Diadesmis confervacea, Nitzschia amphibia e Achnanthidium exiguum preferem temperaturas acima dos $25^{\circ} \mathrm{C}$, e Achnanthidium subhudsonis, Karayevia oblongella, Planothidium frequentissimum e Planothidium lanceolatum temperaturas inferiores a $25^{\circ} \mathrm{C}$ (Figura 17.5). Os locais com maior diversidade de espécies de diatomáceas localizam-se na confluência das águas termais com o rio Minho (Termas da Chavasqueira e Outariz). As águas termais com menor influência de água dos rios mostram menor diversidade 37 .
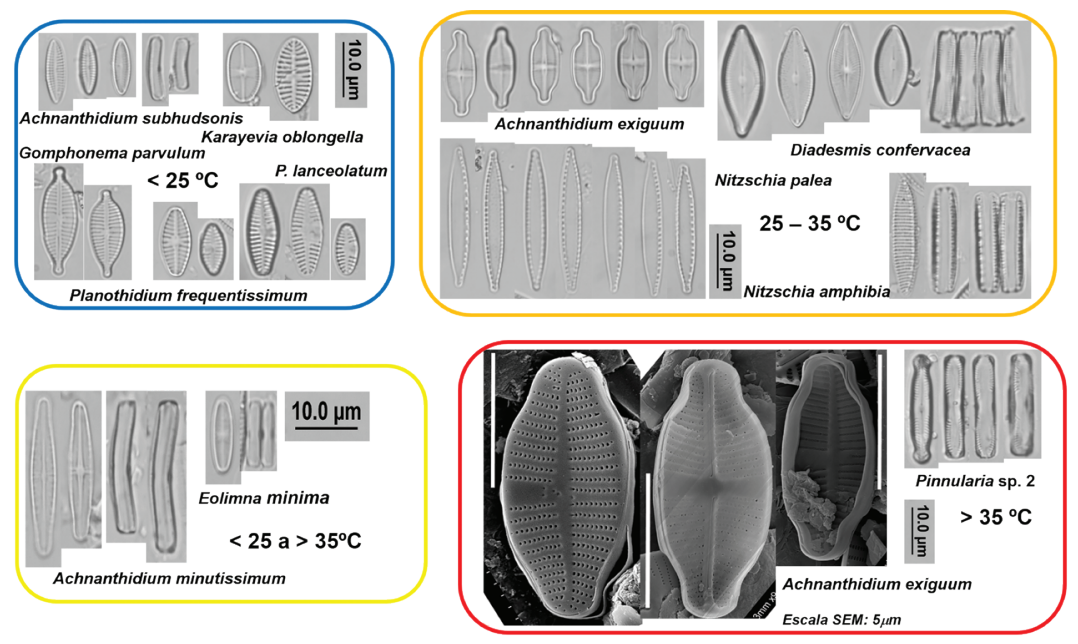

Figura 17.5. Espécies de diatomáceas que aparecem em águas termais no noroeste da Península Ibérica.

\section{Outras leituras}

Beyond Lisbon: http://www.beyondlisbon.pt/cat-thermal.html

Carlos Franquinho: http://carlos.franquinho.info/2011/04/a-energia-geotermicaem-portugal/

Infopédia: https://www.infopedia.pt/\$energia-geotermica 
Laboratório Nacional de Energia e Geologia espaço web (LNEG): http://www.lneg. pt/CienciaParaTodos/edicoes_online/diversos/rec_geotermicos

Lourenço M.C. 1998. Recursos geotérmicos em Portugal continental: baixa entalpia. Instituto Geológico e Mineiro. Portugal, Lisboa

Novo Aquilégio: http://www.aguas.ics.ul.pt/

Nuno Correia: http://cienciasdavidaedaterra25.blogspot.com.es/2011/09/aguastermais-minerais-e-de-nascente.html

Portal São Francisco: http://www.portalsaofrancisco.com.br/meio-ambiente/aguamineral

\section{Referências bibliográficas}

${ }^{1}$ Khater A.E.M. 2003. Radiological aspects of some Egypcian Thermo-mineral springs. J. Environ. Monitor. 5: 414-418

${ }^{2}$ Košić K., Pivac T., Romelić J., Lazić L. \& Stojanović V. 2011. Characteristics of thermal-mineral waters in Backa region (Vojvodina) and their exploitation in spa tourism. Renew. Sustainable Energy Rev. 15: 801-807

${ }^{3}$ Glazier, D.S. 2009. Springs. In: Likens G.E. (ed.) Encyclopedia of inland waters, vol 1. Academic Press. U.S.A., San Diego, pp. 734-755

${ }^{4}$ Stavreva-Veselinovska S. \& Todorovska A. 2010. Ecology of the diatomic flora in Thermo Mineral springs of Katlanovska Banja in the Republic of Macedonia. Ecol. Balk. 2: 1-6

${ }^{5}$ Directiva 2009/54/CE do Parlamento Europeu e do Conselho de 18 de Junho de 2009 relativa à exploração e à comercialização de águas minerais naturais (Reformulação). J. Oficial da União Europeia 164/45

${ }^{6}$ Barbier E. 2002. Geothermal energy technology and current status: an overview. Renew. Sust. Energ. Rev. 6: 3-65

${ }^{7} \mathrm{O}^{\prime}$ Gorman E.J., Benstead J.P., Cross W.F., Friberg N., Hood J.M., Johnson P.J., Sigurdssons B.D. \& Woodward G. 2015. Climate change and geothermal ecosystems: natural laboratories, sentinel systems, and future refugia. Global Change Biol. 20: 3291-3299

${ }^{8}$ Castenholz R.W. 1996. Endemism and biodiversity of thermophilic cyanobacteria. Nova Hedwigia Beih. 112: 33-47

${ }^{9}$ Pinheiro A.J.A. 2011. Ocorrências hidrominerais associadas ao acidente Gerês-Lobios: conceptualização do funcionamento hidrogeológico do sistema hidrotermal. Tese de mestrado. Universidade do Minho. Portugal, Braga

${ }^{10}$ Instituto Geológico e Mineiro. 1998. Recursos geotérmicos em Portugal continental: baixa entalpia. Ministério de Economia e Instituto Geológico e Mineiro. Portugal, Lisboa

${ }^{11}$ Lepierre, C. 1930-31. Chimie et Physico-Chimie des Eaux. In: Indústrias Gráficas (ed.) Le Portugal hydrologique et climatique. Portugal, Lisboa, pp. 75-106 
${ }^{12}$ Carvalho M.J. \& Carvalho M.R. 2004. Geothermal resources and applications in Portugal. Cad. Lab. Xeol. Laxe 29: 97-117

${ }^{13}$ Marques J.M, Matias M.J., Basto M.J., Carreira P.M., Aires-Barros L.A \& Goff F. E. 2010. Hydrothermal alteration of Hercynian granites, its significance to the evolution of geothermal systems in granitic rocks. Geothermics 39: 152-160

${ }^{14}$ Calado C. 1995. Carta das Nascentes Minerais: Notícia explicativa. Atlas do Ambiente. Direcção-Geral do Ambiente. Portugal, Lisboa

${ }^{15}$ Aires-Barros L, Marques J.M. Graça R.C., Matias M.J., Van der Weijden C., Kreulen R. \& Eggenkamp H.G.M. 1998. Hot and cold $\mathrm{CO}_{2}$-rich mineral waters in Chaves Geothermal area (Northern Portugal). Geothermics 27: 89-10

${ }^{16}$ Cruz J.V. \& França Z. 2006. Hydrogeochemistry of thermal and mineral water springs of the Azores archipelago (Portugal). J. Volcanol. Geotherm. Res. 151: 382-398

${ }^{17}$ Freire P., Andrade C., Viveiros F., Silva C., Coutinho R. \& Cruz J.V. 2015. Mineral water occurrence and geochemistry in the Azores archipelago (Portugal): insight from an extended database on water chemistry. Environ. Earth Sci. 73: 2749-2762

${ }^{18}$ Brock, T.D. 1967. Life at high temperatures. Science 158: 1012-1019

${ }^{19}$ Brock T. D. 2001. The origins of research on thermophiles. In: Reysenbach A.-L., Voytek M. \& Mancinelli R. (eds.) Thermophiles: Biodiversity, Ecology and Evolution. Kluwer Academic/Plenum Publishers. U.S.A., New York, pp. 1-9

${ }^{20}$ Werh J.D. \& Sheath R.G. 2015. Habitats of Freshwater Algae. In: Wehr J.D. \& Sheath R.G. (eds.) Freshwater Algae of North America, $2^{\text {nd }}$. Academic Press. U.S:A., San Marcos , pp.13-74

${ }^{21}$ Breitbart M., Wegley L., Leeds S., Schoenfeld T. \& Rohuer F. 2004. Phage community dynamics in hot springs. Appl. Environ. Microbiol. 70: 1633-1640

${ }^{22}$ Aguiar P., Beveridge T.J. \& Reysenbach A.L. 2004. Sulfuribydrogenibium azorense, sp. nov., a thermophilic hydrogen-oxidizing microaerophile from terrestrial hot springs in the Azores. Int. J. Syst. Evol. Microbiol. 54: 33-39

${ }^{23}$ Camara J., Pereira C.L., Gonçalves V., Medeiros J., Nunes J.C., Sá H., Gaspar C., Raposo J.P. \& Aguiar P. 2010. Variation on chemical composition among microbial biofilms from Furnas hotsprings, S. Miguel, Azores. 13th International Society for Microbial Ecology Conference. U.S.A., Seattle pp. 149

${ }^{24}$ Pereira C.L., Gonçalves V. \& Aguiar P. 2010. Cyanobacteria diversity in Furnas termal mats, S. Miguel, Azores. XV Congresso da Associação Ibérica de Limnologia. Portugal, Ponta Delgada, pp. 88

${ }^{25}$ Quintela A., Almeida S., Terroso D., Ferreira da Silva E., Forjaz V. \& Rocha F. 2013. Diatom assemblages of thermal and mineral waters from volcanic environments in São Miguel Island, Azores. Diatom Res. 28: 407-417

${ }^{26}$ Luz R., Cordeiro R., Rosa G., Barreto C. \& Gonçalves V. 2017. Biological activity of extracts of cyanobacteria isolated from lakes and thermal waters from the Azores islands. I Congresso Iberoamericano de Cianotoxinas. Espanha, Lugo, pp. 22

${ }^{27}$ Ward D.M., Castenholz R.W. \& Miller S.R. 2012. Cyanobacterial in geothermal habitats. In: Whitton B.A. (ed.). Ecology of cyanobacterial II: their diversity in time and space. Springer, Science + Bussiness Media BV. U.S.A., New York, pp. $39-64$ 
${ }^{28}$ Finsinger K., Scholz I., Serrano A., Morales S., Uribe-Lorio L., Mora M., Sittenfeld A., Weckesses J. \& Hess W.R. 2008. Characterization of true-branching cyanobacteria from geothermal sites and hot spring of Costa Rica. Environ. Microbiol. 10: $460-473$

${ }^{29}$ Stockner J.G. 1967. Observations of the thermophilic algal communities in Mount Rainier and Yellowstone National Parks. Limnol. Oceanogr. 12: 13-17

${ }^{30}$ Kashefi K. \& Lovley DR. 2003. Extending the upper temperature limit for life science. Science 301: 934

${ }^{31}$ Comissão Europeia. 2000. Directiva 2000/60/CE do Parlamento Europeu e do Concelho de 23 de Outubro de 2000, que estabelece um Quadro de Acção Comunitária no Domínio da Politica da Água. J. Oficial Com. Europeias L327: $1-72$

${ }^{32}$ Owen R.B., Renaut R.W. \& Jones B. 2008. Geothermal diatoms: a comparative study of floras in hot springs systems of Iceland, New Zealand and Kenya. Hydrobiologia 610: $175-192$

${ }^{33}$ Mpawenayo B. \& Mathooko J.M. 2004. Diatom assemblages in the hot springs associated with Lakes Elmenteia and Baringo in Kenya. African J. Ecol. 42: $363-367$

${ }^{34}$ Noguerol A. 1991. Algas de fuentes termales del NW de España: Baños de Molgas y Caldas de Partovia. Acta Bot. Malac. 16: 27-30

${ }^{35}$ Leira M., Meijide-Failde R. \& Torres E. 2017. Diatom communities in thermo-mineral springs in Galicia (NW Spain). Diatom Res. 32: 29-42

${ }^{36}$ Delgado C., Feio M.J., Pardo I. \& Almeida S.F.P. 2016. Diatom communities from thermal springs in NW Iberian Peninsula. Congress Programme SIL (International Society of Limnology). Italy, Turin, pp. 319-320

${ }^{37}$ Delgado C., Feio M.J., Pardo I e Almeida S.F.P. 2019. Benthic diatom communities from springs' thermal gradients: insights of water temperature effects. Plant. Ecol. Divers in press 